\title{
Enhancement of Heat Transfer using Aluminum Oxide Nanofluid on Smooth and Finned Surfaces with COMSOL Multiphysics Simulation in Turbulent Flow
}

\author{
Hasan S. Majdi ${ }^{1}$, Hussein A. Alabdly ${ }^{2}$, Muayad F. Hamad ${ }^{2}$, Basim O. Hasan ${ }^{2 *}$, Mustafa M. Hathal ${ }^{1}$
}

\author{
Authors affiliations: \\ 1) Department of Chemical \\ Engineering and Petroleum \\ Industries, Al-Mustaqbal University \\ College, Iraq.
}

2) Dep. of Chemical Eng., AlNahrain University, Baghdad, Iraq

*) Corresponding author: basimohasan13@gmail.com, basimhasan2017@eng.nahrainuniv.edu.iq

\section{Paper History:}

Received: $5^{\text {th }}$ Feb. 2019

Revised: $5^{\text {th }}$ March 2019

Accepted: $18^{\text {th }}$ March. 2019

\begin{abstract}
Both surface extension and nanofluid methods were used to enhance the heat transfer in a double pipe heat exchanger under turbulent flow conditions. Aluminum oxide nanoparticles were used with different concentrations $(0.6-3 \mathrm{~g} / \mathrm{l})$ in hot water to increase the heat transfer rate on smooth tube and circular fins tube for a range of Reynolds number424019790. The simulation was also performed to predict the heat transfer coefficient and temperature profile for selected conditions in which COMSOL Multiphysics is used. The experimental results revealed that the heat transfer enhancement by both circular fin and nanofluid exhibited an increasing trend with Reynolds number and nanofluid concentration. The conjoint effect of $\mathrm{Al}_{2} \mathrm{O}_{3}$ of $3 \mathrm{~g} / \mathrm{l}$ concentration and circular fin provided largest heat transfer enhancement of $53 \%$ for the highest Re investigated. Simulation results showed reasonable agreement with the experimental values of heat transfer coefficient. The simulation showed that the presence of nanofluid on finned surface influenced the temperature profile indicating the increased heat transfer rate.
\end{abstract}

Keywords: Heat Transfer; Enhancement; Nanofluid; Fin; Turbulent Flow.

\author{
Nomenclature \\ A Area, $\mathrm{m}^{2}$ \\ C Concentration of nanoparticles, $\mathrm{g} / \mathrm{L}$ \\ Cp Specific heat, J/kg. K \\ $\mathrm{L}$ Length, $\mathrm{m}$ \\ $\mathrm{m}$ Mass flow rate, $\mathrm{kg} / \mathrm{s}$ \\ Q Heat transfer rate, W \\ Re Reynolds number \\ $\mathrm{T}$ Temperature, $\mathrm{K}$ \\ $\mathrm{U}_{\mathrm{o}}$ Overall heat transfer coefficient based on
} outside area, $\mathrm{W} / \mathrm{m}^{2} . \mathrm{K}$

Subscripts

c cold

h hot

Abbreviations

CFD Computational fluid dynamics

lm log-mean

\section{Introduction}

The augmentation of heat transfer is of a practical significance to increase the effectiveness of heat exchangers. For several decades ago, this issue was a concern of the researchers. This was because of the wide applications of heat exchangers in industrial processes such as power generation, cooling and heating systems, and chemical and petrochemical processes.

In practice, there are several ways to increase the efficiency of heat exchange between hot and cold process fluids. These are: the use of fins, the use inserts, and the use of fine particles added to the process fluid. These three ways are still under extensive research to investigate the optimum conditions for heat exchanger operation. The use of extended surfaces (fins and inserts) of different geometries is proved very successful to enhance the heat transfer rate and reduce the equipment sizes. The advantage of this method is that it is inexpensive and easy to install often. However, the disadvantage of this method is the increase of pressure drop and heat exchanger weight and thus the manufacturing cost. Observing literature indicates different findings for the enhancement obtained by different fin and insert geometries. The percentage of heat transfer enhancement associated with each type of extended surface is dependent on the physical properties of fluid, flow velocity, and surface material and roughness.

Solid particles (metallic, non-metallic, or polymeric) of millimeter of micrometer sizes have been used by several previous works [1-3] to enhance the heat transfer. Under certain conditions this method gives reasonable heat transfer enhancement. However, this size of particles has several drawbacks such as increased pressure drop, erosion of metal surface, clogging of flow channel, accumulation in a certain zone of flow system, etc.In general, despite the slurries have relatively high thermal conductivities; they are practically not successful for heat transfer enhancement[4].

In the past 15 years, attempts are made to improve thermal characteristics of process fluid by adding nano sized particles of high thermal conductivity to the process fluid. In this case, the produced nanofluids have high thermal conductivity

NJES is an open access Journal with ISSN 2521-9154 and eISSN 2521-9162

This work is licensed under a Creative Commons Attribution-NonCommercial 4.0 International License 
to enhance the heat transfer rate. Different materials and sizes of nano-particles are used for increasing the heat transfer efficacy such as TitinumoxidTiO ${ }_{2}$ [4], copper oxide $(\mathrm{CuO})[5,6,7]$ aluminum oxide $\left(\mathrm{Al}_{2} \mathrm{O}_{3}\right)$ $[5,8]$, iron oxide $\mathrm{Fe}_{2} \mathrm{O}_{3}[9], \mathrm{CeO}[10]$ and others for different systems under different operating conditions. Previous results of nanofluids indicated different percentage of heat transfer enhancement [4,8,11-13] while others [6] showed increasing decreasing trend of heat transfer rate with nanoparticle concentration. In addition, there is a noticeable pressure drop increase when using relatively high concentration of nanoparticle [4]. The thermal conductivity of the used nanoparticle plays important role in the heat transfer enhancement. The nanofluids have good long-term stability and rheological properties compared to micrometer or millimeter-sized suspensions [4].

Aluminum and copper particles are the most used materials. Although copper is superior from the standpoint of thermal conductivity, aluminum is the more common choice because of its high thermal conductivity and low cost. Good reviews for the studies that have used the nanofluids for heat transfer enhancement are presented elsewhere $[4,5,8,12]$.

In general, studies concerning the effect of flow hydrodynamic on the heat transfer enhancement by nanofluidare limited in open literature. This matter is still requiring further investigation for different types and concentrations of nanofluids especially on extended surfaces. The aim of the present work is to investigate the effect of using aluminum oxide nanofluid on the overall heat transfer coefficient of smooth and finned tube surfaces under turbulent flow conditions.

\section{Experimental}

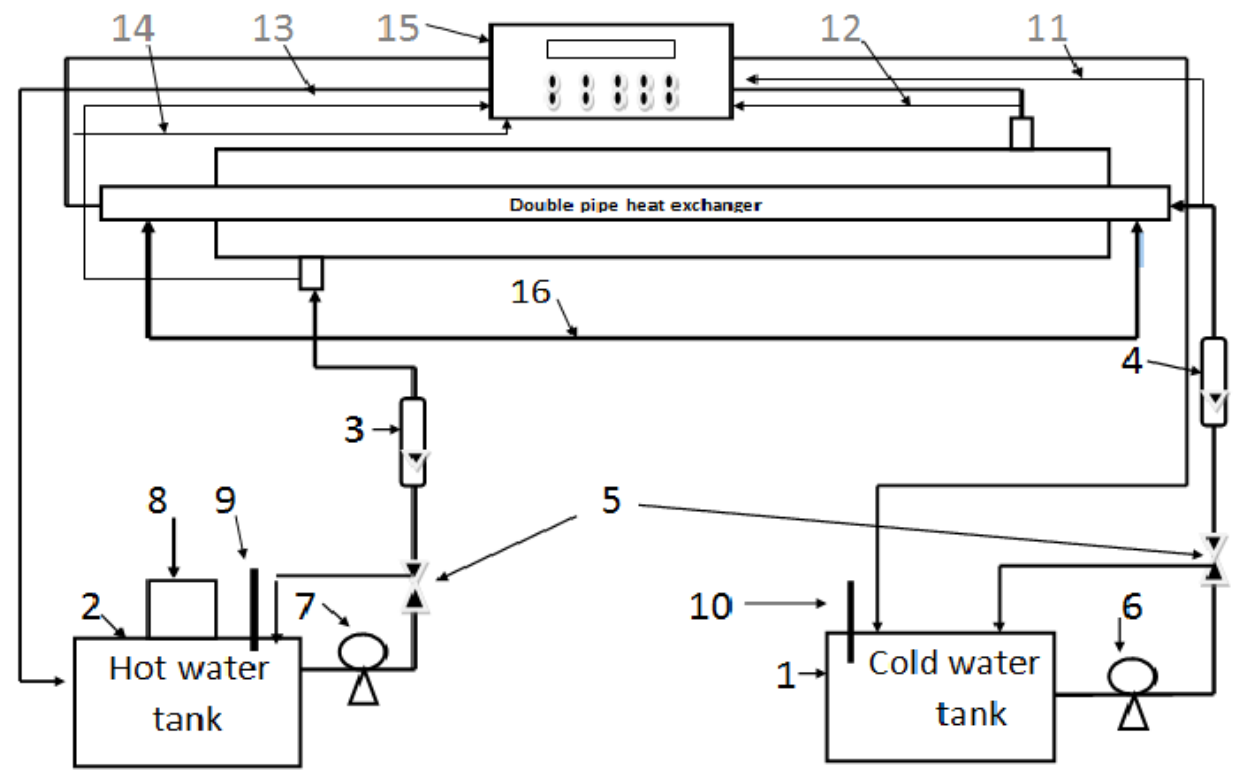

Figure (1): Experimental set up, 1-water chiller, 2-hot fluid tank, 3-rotameter for the hot fluid ,4-rotameter for cold fluid,5-valves ,6-cold fluid pump ,7-hot fluid pump ,8-heater, 9- thermometer for hot fluid,10- thermometer for cold fluid, 11- thermocouple 1,12-thermocouple 2, 13-thermocouple 3,14-thermocouple 4, 15-computerized temperature recorder (data logger). 
The inlet and outlet temperature of nanofluid and cold water were recorded to estimate the overall heat transfer coefficient based on the outside surface area of inner tube using:

$$
\mathrm{U}_{\mathrm{o}}=\frac{\mathrm{Q}}{\mathrm{A}_{\mathrm{o}} \Delta \mathrm{Tlm}}
$$

Where is the heat transfer rate between fluids calculated as:

$$
\mathrm{Q}=\mathrm{m}_{\mathrm{h}} \mathrm{cp}_{\mathrm{h}}\left(\mathrm{T}_{\mathrm{hi}}-\mathrm{T}_{\mathrm{ho}}\right)
$$

$A_{\circ}$ is the outside surface area of the inner tube and $\Delta \mathrm{T}_{\mathrm{lm}}$ the log-mean temperature difference. Each experiment was carried out twice. The temperatures were recorded at each 5 seconds via data logger. In each run 80 measurements were recorded. The average value was taken for calculating the heat transfer coefficient with the physical properties considered at the bulk temperature.

\section{CFD simulation}

Computational fluid dynamic simulation using COMSOL Multiphysics CFD package for a selected condition was used to predict the heat transfer coefficient and temperature profile in in the presence and absence of nanofluid for smooth and finned surfaces. The COMSOL solves the continuity, momentum and energy equation for the system to predict the heat transfer coefficient and temperature distribution in axially, radially, and tangentially.

\section{Results and Discussion}

Figure 2 shows the variation of overall heat transfer coefficient $\left(\mathrm{U}_{\mathrm{o}}\right)$ with hot water (base fluid) Reynolds number $\left(\mathrm{Re}_{\mathrm{h}}\right)$ for smooth and finned surfaces. It is evident that $\mathrm{U}_{\mathrm{o}}$ increases linearly with $\mathrm{Re}_{\mathrm{h}}$ for both cases. The circular fin tube exhibits higher heat transfer coefficient for the whole range of $\mathrm{Re}_{\mathrm{h}}$. The average heat transfer enhancement by using circular fin is $24 \%$. The higher heat transfer rate of circular fin is attributed to the increased area of contact and higher interaction between the wall and the fluids [16, 17]. In addition, the presence of fins increases the surface roughness which in turn increases the turbulence level in the wall region leading to increases heat transfer rate [18-21]. The fins handle the heat from the wall to the bulk of cold fluid which promotes the heat transfer, i.e. the higher the interaction between fins and fluid is the higher the heat transfer rate [22]. Figure 3 shows the effect of adding different amounts of Alumina nanoparticles on $U_{0}$ for the smooth tube for the entire investigated range of $\mathrm{Re}_{\mathrm{h}}$. It can be seen that the nanofluid of various concentration causes a clear increase on the overall heat transfer coefficient. The figure reveals that highest heat transfer enhancement occurs at highest concentration of nanofluids $(3 \mathrm{~g} / \mathrm{L})$. Baba et al. [9] found that the heat transfer rate increases with increasing iron oxide nanoparticle up to $0.4 \%$. The addition of nanoparticles enhances the heat transfer rate by the following ways [23]: by increasing the thermal conductivity of the fluid, by increasing the heat capacity of the fluid, and increased turbulence in the wall region.

Figure 4 shows the trend of $U_{0}$ with nanofluid concentration for different $\mathrm{Re}_{\mathrm{h}}$ for smooth tube. It can be seen that the increase is linear for all $\mathrm{Re}_{\mathrm{h}}$. However, at low $\operatorname{Re}_{h}$ the increase of $\mathrm{U}_{\mathrm{o}}$ with the concentration is slight. The higher the $\mathrm{Re}_{h}$ is the higher the increase of $\mathrm{U}_{0}$ with nanofluid concentrations. This can be ascribed to the fact that with increasing $\mathrm{Re}_{\mathrm{h}}$, the turbulence level increases which leads to an increase in the collision event between nanoparticles and the wall. In addition, the dispersion of nanoparticles in the fluid increases with the increased turbulence which increases the effective thermal conductivity resulting in an increased heat transfer rate. This agrees with the observation of Hathal [24] for copper oxide nanofluid and Baba et al. [9] for iron oxide nanofluid.

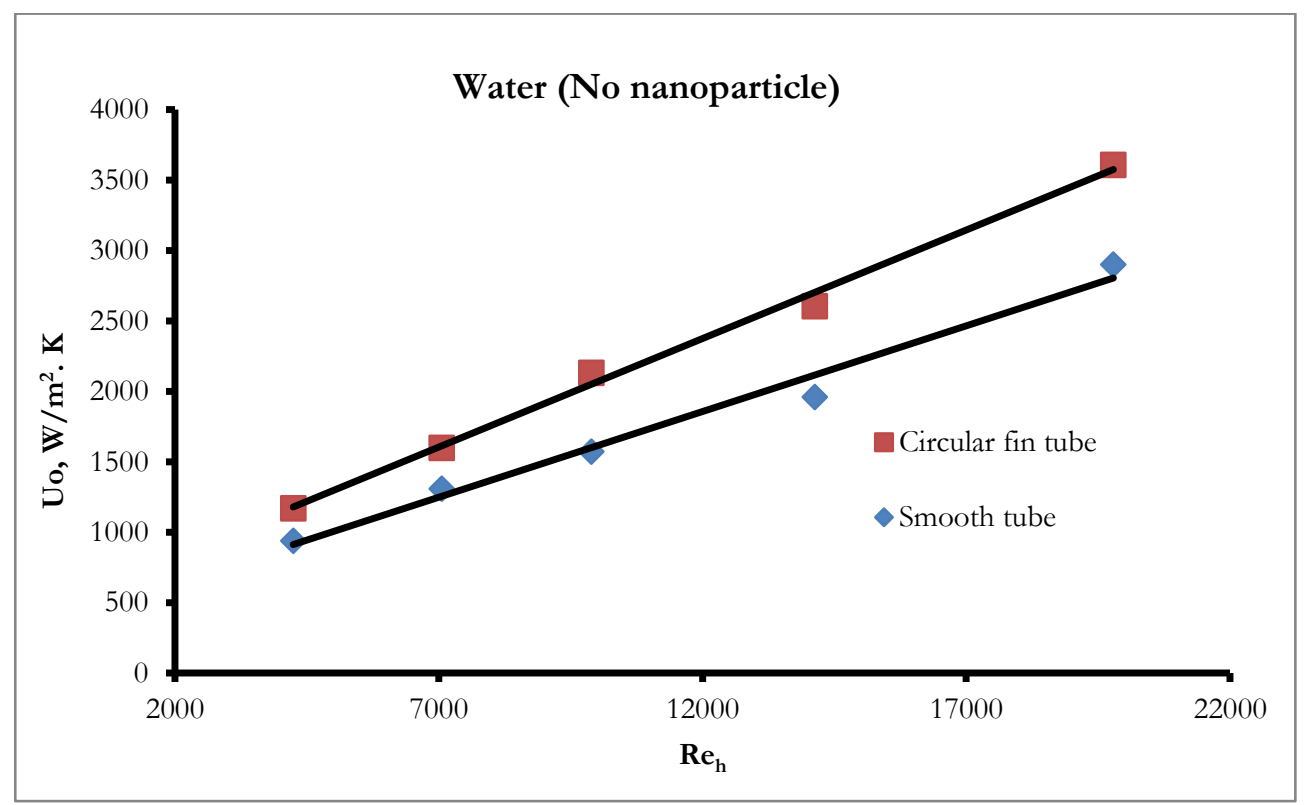

Figure (2): Comparison of $\mathrm{U}_{\mathrm{o}}$ vs. $\mathrm{Re}_{\mathrm{h}}$ for smooth tube and circular fin tube. 


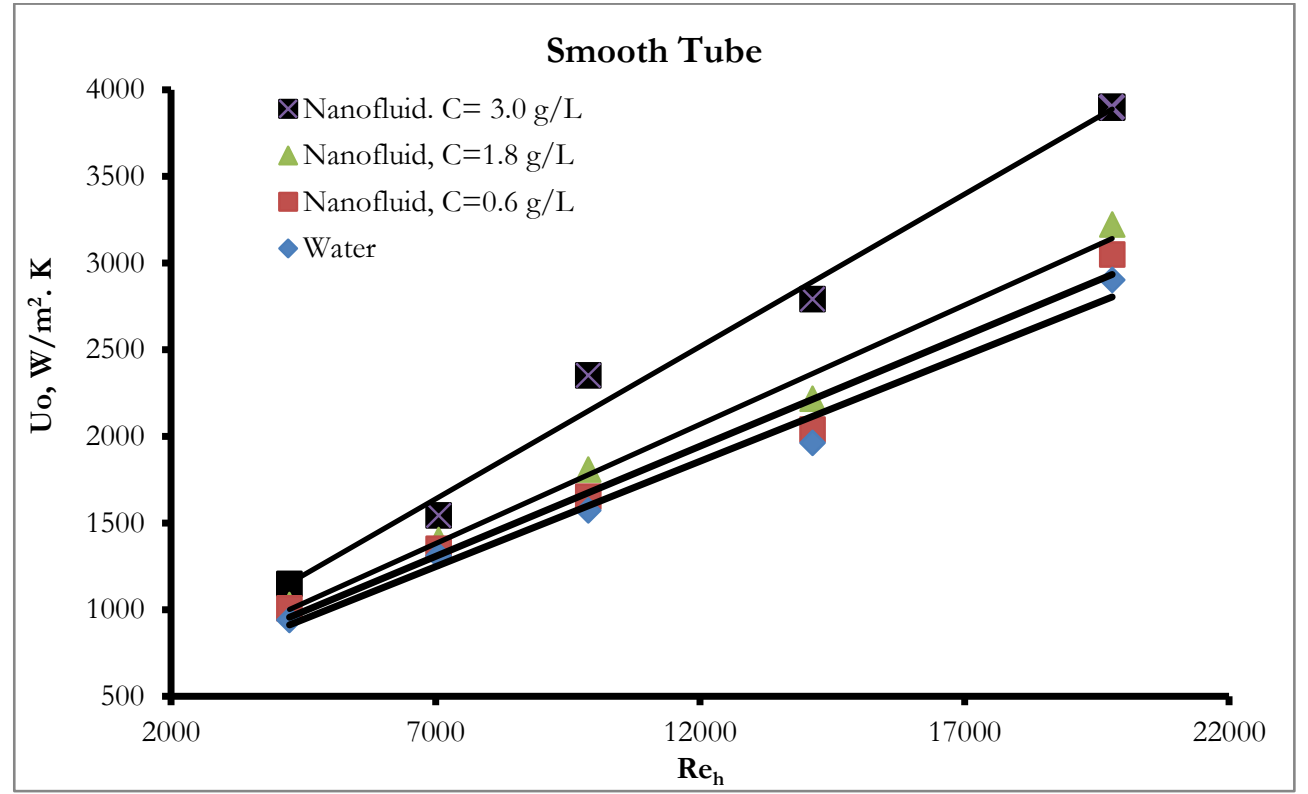

Figure (3): Heat transfer coefficient vs. $\mathrm{Re}_{\mathrm{h}}$ for different nanofluid concentrations for smooth tube.

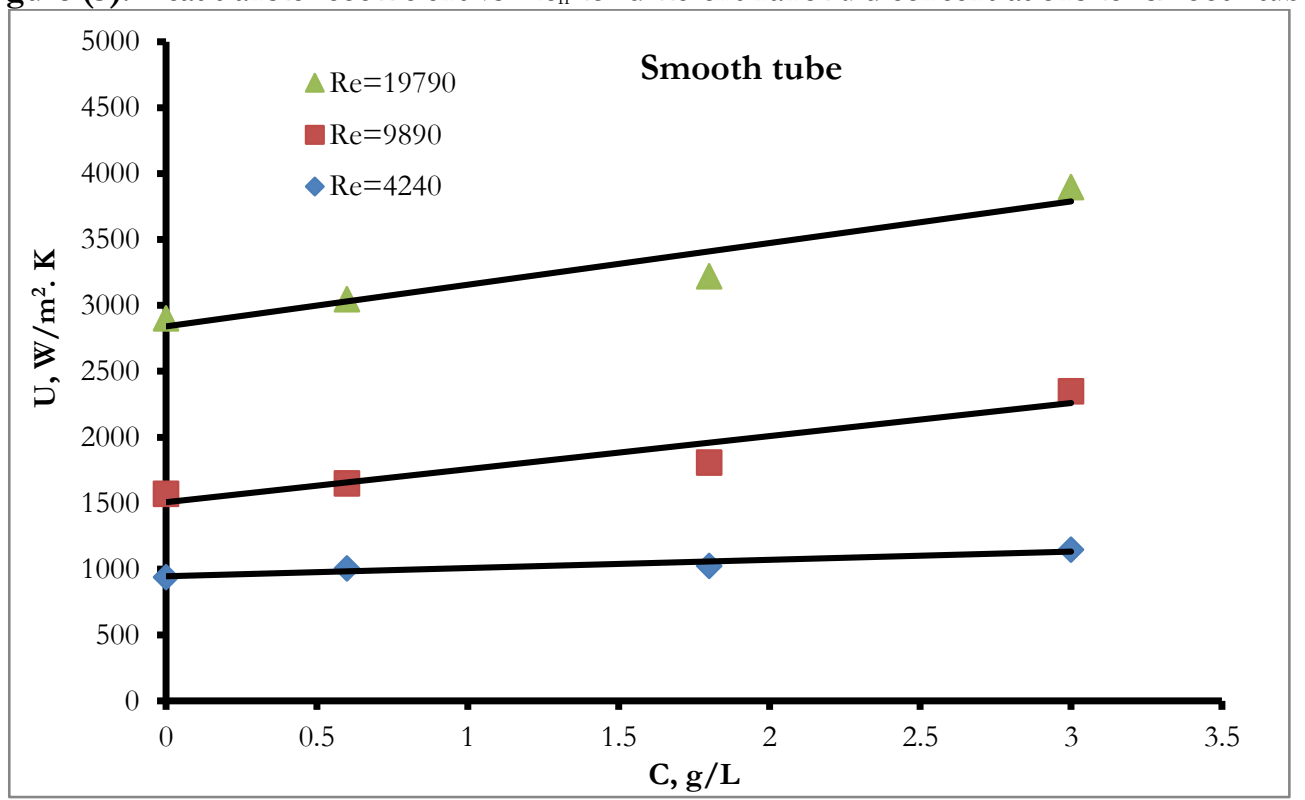

Figure (4): Heat transfer coefficient vs. nanofluid concentration for different Re for smooth tube.

Figure 5 presents $U_{o}$ versus $\operatorname{Re}_{h}$ for circular fin tube at different nanofluid concentration. It reveals that increasing $\mathrm{Re}_{\mathrm{h}}$ leads to linear increase in $\mathrm{U}_{\mathrm{o}}$ for all values of concentrations. This is ascribed to the increased thermal eddy diffusion by increased turbulence level at the wall $[25,26]$. The increased turbulence in the wall vicinity causes a reduction the thermal boundary layer thickness that restrains the heat transfer [27-29]. Figure 5 also reveals that the higher the nanofluid concentration is the higher the $\mathrm{U}_{\mathrm{o}}$. Figure 6 shows the trend of $\mathrm{U}_{\mathrm{o}}$ with nanofluid concentration for different $\mathrm{Re}_{\mathrm{h}}$ on finned surface. It can be seen that the trend is linear for all $R_{h}$. Again, for lower $\mathrm{Re}_{\mathrm{h}}$ the increase in $\mathrm{U}_{\mathrm{o}}$ with concentration is slight while for high Re the increase is appreciable. Figure 7 through 9 show a comparison of the overall heat transfer coefficient between smooth and fined tube with nanofluid as a working fluid in the shell. The figures indicate that the heat transfer coefficient in the presence of nanofluid is higher than in the case of finned tube for the whole range of $\mathrm{Re}_{\mathrm{h}}$. 


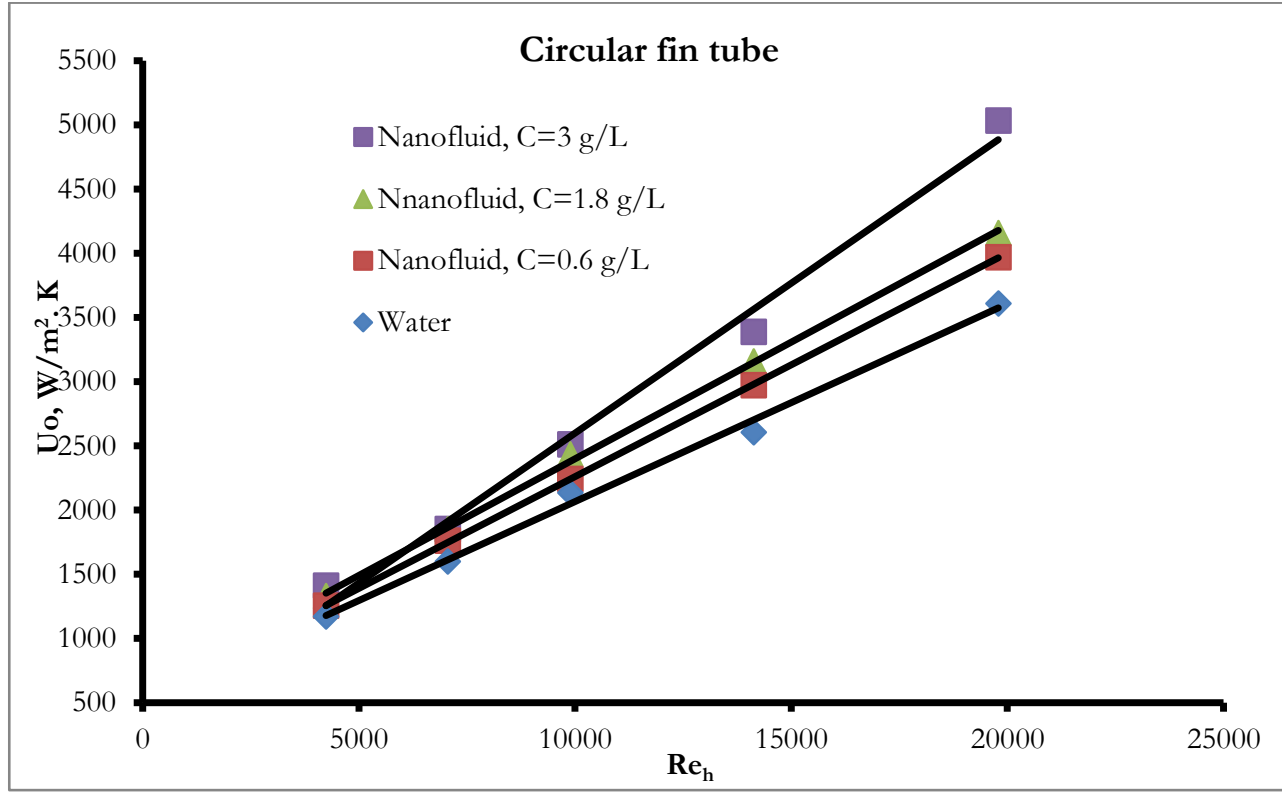

Figure (5): Heat transfer coefficient vs. $\mathrm{Re}_{\mathrm{h}}$ for different nanofluid concentration for circular fin tube.

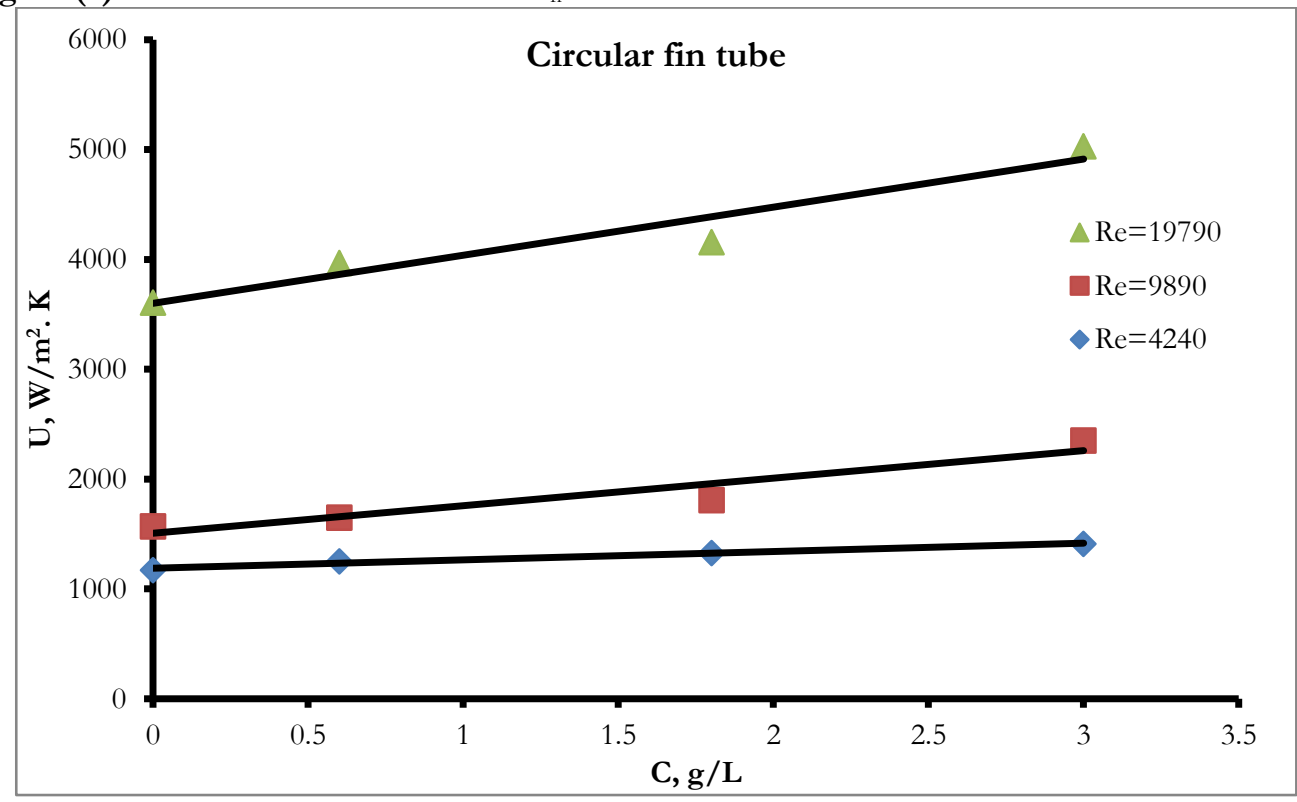

Figure (6): Heat transfer coefficient vs. nanofluid concentration for circular fin for different $\mathrm{Re}_{\mathrm{h}}$

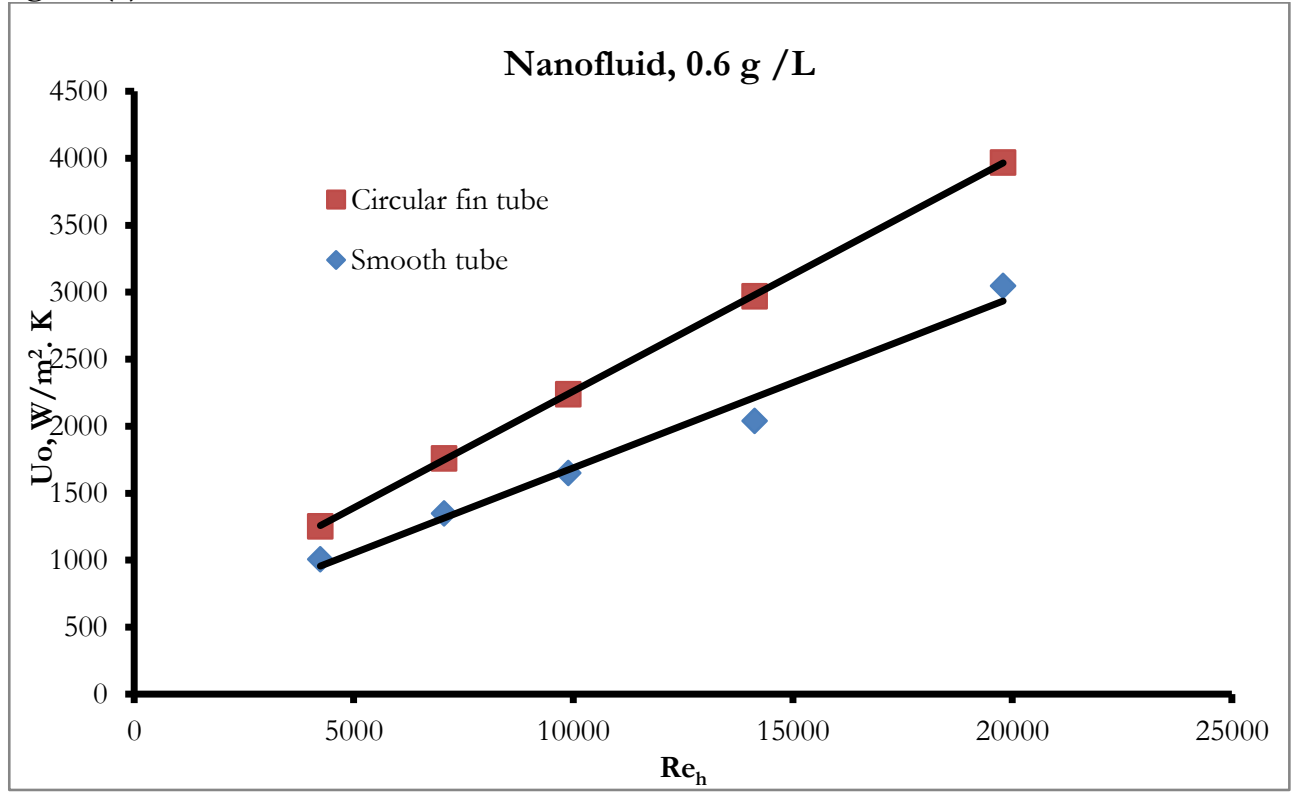

Figure (7): Comparison of $U_{o}$ vs. $R_{h}$ between smooth and enhanced surface for $C=0.6 \mathrm{mg} / \mathrm{L}$. 


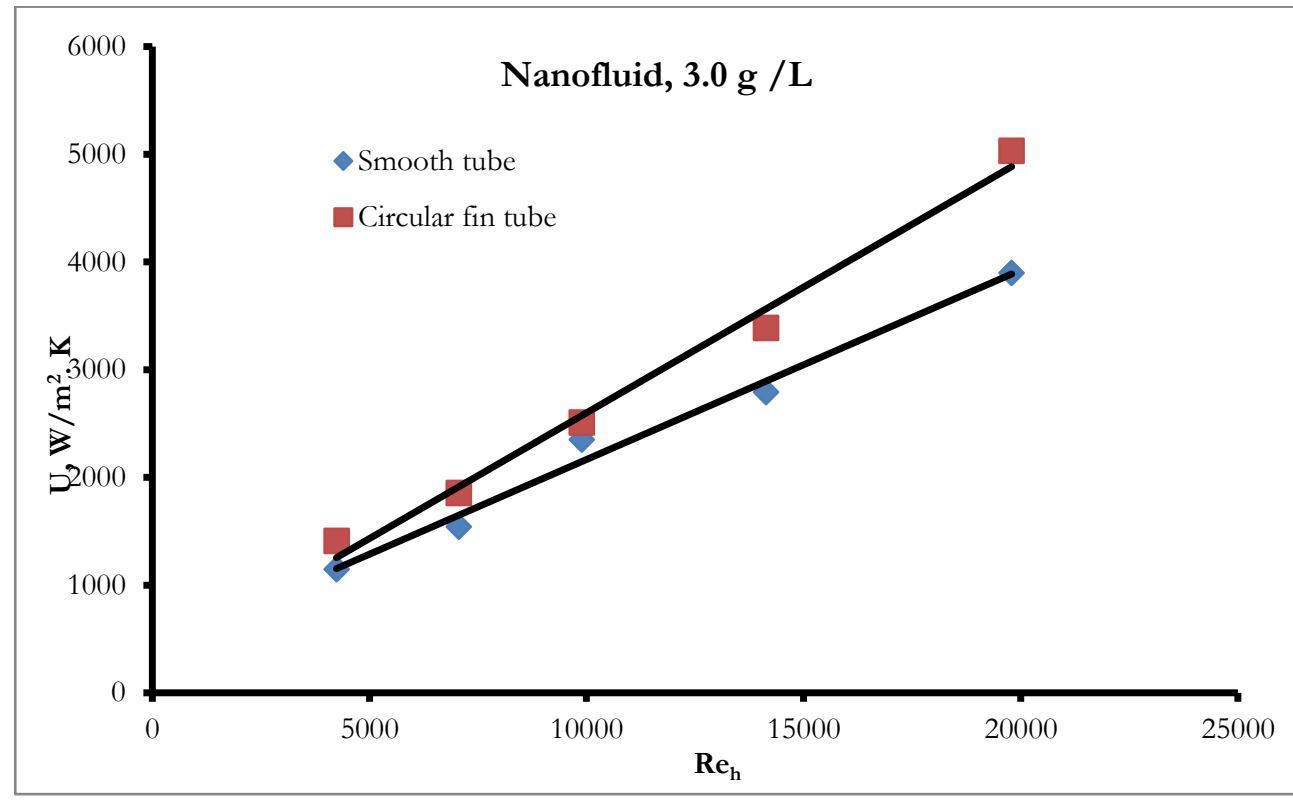

Figure (8): Comparison of $U_{o}$ vs. $R_{h}$ between smooth and enhanced surface for $C=3 \mathrm{mg} / \mathrm{L}$.

Table 1 lists the percentage of heat transfer enhancement by using circular fin tube calculated as:

$$
\text { Enhancement } \%=\frac{\mathrm{Uo}, \mathrm{f}-\mathrm{Uo}, \mathrm{i}}{\mathrm{Uo,i}}
$$

Where $i$ and $f$ denote initial and final condition respectively. For Table 1 the initial condition is the smooth surface and the final condition is the finned surface. It is clear that the enhancement increases with increasing $\operatorname{Re}$ and it ranges from $24.6 \%$ to $38.6 \%$ with average value of $30.7 \%$. Table 2 shows the heat transfer enhancement by nanofluid on smooth and finned surface calculated using Eq. (2). In Table 2 the initial condition is without nanofluid (water) and the final condition is with nanofluid. It can be seen that there is a considerable enhancement by nanofluid for both smooth and finned surface. The enhancement percent in the case of finned tube is generally higher than the case smooth tube by an average of $5 \%$ for entire range of $\mathrm{Re}_{\mathrm{h}}$ and concentrations. In addition, the enhancement percent has no stable trend with $\mathrm{Re}_{\mathrm{h}}$. Table 2 also reveals that the enhancement increases with the increase of nanoparticle concentration for both smooth and finned tubes. For the concentration of $3 \mathrm{~g} / \mathrm{L}$ the average increase is reaches $33.1 \%$ for smooth surface while for circular fins surface it is $17 \%$. Table 3 lists the values of heat transfer enhancement associated with the use of both finned surface and nanofluid. In this case the enhancement is compared with the case of smooth surface with water as a working fluid. It can be seen that high heat transfer enhancement obtained by the combined effect of fins and nanofluid ranges from $26.6 \%$ to $62.1 \%$ depending on the $\mathrm{Re}_{\mathrm{h}}$ and nanofluid concentration. It is evident that the enhancement increases with the increase in nanoparticle concentration but it has no steady trend with $\mathrm{Re}_{\mathrm{h}}$. Examining the literature indicates that several studies agree with the present findings. Albadr et al. [8] found $62 \%$ enhancement under turbulent flow condition by using $2 \%$ volume concentration of alumia nanofluid in shell and tube heat exchanger.
The results Duangthongsuk and Wongwises [4] revealed $12 \%$ average improvement in heat transfer coefficient by using $2 \%$ volume alumina nanofluid in turbulent flow. Jwo et al. [30] notices $18 \%$ enhancement using 1\% wt Alumina nanoparticles. Khalifa and Banwan [11] obtained 23\% heat transfer enhancement by using $1 \%$ volume alumina nanofluid of particle size $10 \mathrm{~nm}$.

Table (1): Enhancement percent by finned surface (initial condition is the smooth surface).

\begin{tabular}{|c|c|}
\hline $\mathbf{R e}_{\mathbf{h}}$ & $\mathbf{E n h . \%}$ \\
\hline 4240 & 24.6 \\
\hline 7060 & 22.1 \\
\hline 9890 & 35.6 \\
\hline 14130 & 32.9 \\
\hline 19790 & 38.6 \\
\hline Average & $\mathbf{3 0 . 7}$ \\
\hline
\end{tabular}

Table (2): Enhancement percent by nanofluid of different concentrations, $\mathrm{Re}_{\mathrm{c}}=24000$ (initial condition is without nano).

\begin{tabular}{|c|c|c|c|c|c|c|}
\hline \multirow[b]{2}{*}{ Reh } & \multicolumn{3}{|c|}{ Smooth tube } & \multicolumn{3}{|c|}{ Circular fin tube } \\
\hline & $\begin{array}{c}\text { Enh.\% } \\
\text { for } \\
\text { C=0.62 } \\
\text { g/L }\end{array}$ & $\begin{array}{c}\text { Enh. } \\
\% \text { for } \\
C=1.8 \\
\text { g/L }\end{array}$ & $\begin{array}{l}\text { Enh. } \\
\% \text { for } \\
\text { C=3 } \\
\text { g/L }\end{array}$ & $\begin{array}{c}\text { Enh. } \% \\
\text { for } \\
\text { C=0.62 } \\
\text { g/L }\end{array}$ & $\begin{array}{c}\text { Enh. } \% \\
\text { for } \\
C=1.8 \\
\text { g/L }\end{array}$ & $\begin{array}{c}\text { Enh. } \\
\% \text { for } \\
\text { C=3 } \\
\text { g/L }\end{array}$ \\
\hline 4240 & 7.1 & 9.0 & 22 & 7.0 & 13.4 & 20.3 \\
\hline 7060 & 3.0 & 7.1 & 17.7 & 1.0 & 15.6 & 18.7 \\
\hline 9890 & 5.0 & 14.8 & 49.5 & 5.1 & 14.0 & 10.5 \\
\hline 14130 & 3.8 & 13.0 & 42.4 & 14 & 21.2 & 21. \\
\hline 19790 & 5.0 & 11.1 & 34.3 & 10.1 & 15.2 & 28.1 \\
\hline Average & 4.8 & 11 & 33.1 & 9.2 & 15.9 & 17.3 \\
\hline
\end{tabular}

Table (3): Combined enhancement by fins and nanofluid (initial condition is the smooth surface without nano).

\begin{tabular}{|c|c|c|c|}
\hline $\mathbf{R e}_{\mathbf{h}}$ & $\begin{array}{c}\text { Enh.\% by } \\
\text { fin and } \\
\text { nanofluid of } \\
\mathbf{C = 0 . 6 2} \mathbf{g} / \mathbf{L}\end{array}$ & $\begin{array}{c}\text { Enh.\% by } \\
\text { fin and } \\
\text { nanofluid of } \\
\mathbf{C = 1 . 8} \mathbf{g} / \mathbf{L}\end{array}$ & $\begin{array}{c}\text { Enh.\% by } \\
\text { fin and } \\
\text { nanofluid of } \\
\text { C=3 g/L }\end{array}$ \\
\hline 4240 & 26.7 & 41.4 & 50.1 \\
\hline 7060 & 28.0 & 41.1 & 45.0 \\
\hline
\end{tabular}




\begin{tabular}{|c|c|c|c|}
\hline 9890 & 31.2 & 54.7 & 50.1 \\
\hline 14130 & 38.7 & 61.0 & 62.1 \\
\hline 19790 & 29.5 & 43.2 & 59.0 \\
\hline Average & $\mathbf{3 0 . 9}$ & $\mathbf{4 8 . 3}$ & $\mathbf{5 3 . 1}$ \\
\hline
\end{tabular}

Figures 9 and 10 show a comparison between the $\mathrm{U}_{\mathrm{o}}$ obtained by CFD (COMSOL) simulation and the experimental one for a single phase on smooth and finned surfaces. It is evident that the two cases are in a reasonable harmony. Figs. 11 and 12 present a comparison of $\mathrm{U}_{\mathrm{o}}$ vs. $\mathrm{Re}_{\mathrm{h}}$ from experiments and simulation for finned surface for water and for nanofluid respectively. In general, the agreement between the experiments and the simulation is good. Figures 13 show the temperature profile obtained by CFD simulation for the case of smooth tube with water as a working fluid. Figure13a presents the temperature profile around the tube and Figure13b presents a front view of the tube showing the radial temperature profile where the cold water enters into the tube and the hot water leaves the shell. It is evident that there is a clear temperature gradient from the center of the tube, where the temperature is minimum, toward the wall of tube where the color starts to change from yellow to brown. The thermally active region is concentrated close to the wall of inner tube. The darkness of the brown color increases toward the shell inside surface where the temperature becomes maximum. Figures $14 \mathrm{a}$ and $14 \mathrm{~b}$ show the temperature profile for the case where fins and the nanofluid present of $\mathrm{C}=2 \mathrm{~g} / \mathrm{L}$. Comparing Figures $13 \mathrm{~b}$ with $12 \mathrm{~b}$ indicates that the thermally active region is extended from the wall of inner tube toward the inside surface of the shell. That is the color in the shell becomes light brown indicating the decrease of temperature in the shell fluid. This indicates the role of fins and nanofluid to promote the heat transfer from hot nanofluid to cold water.

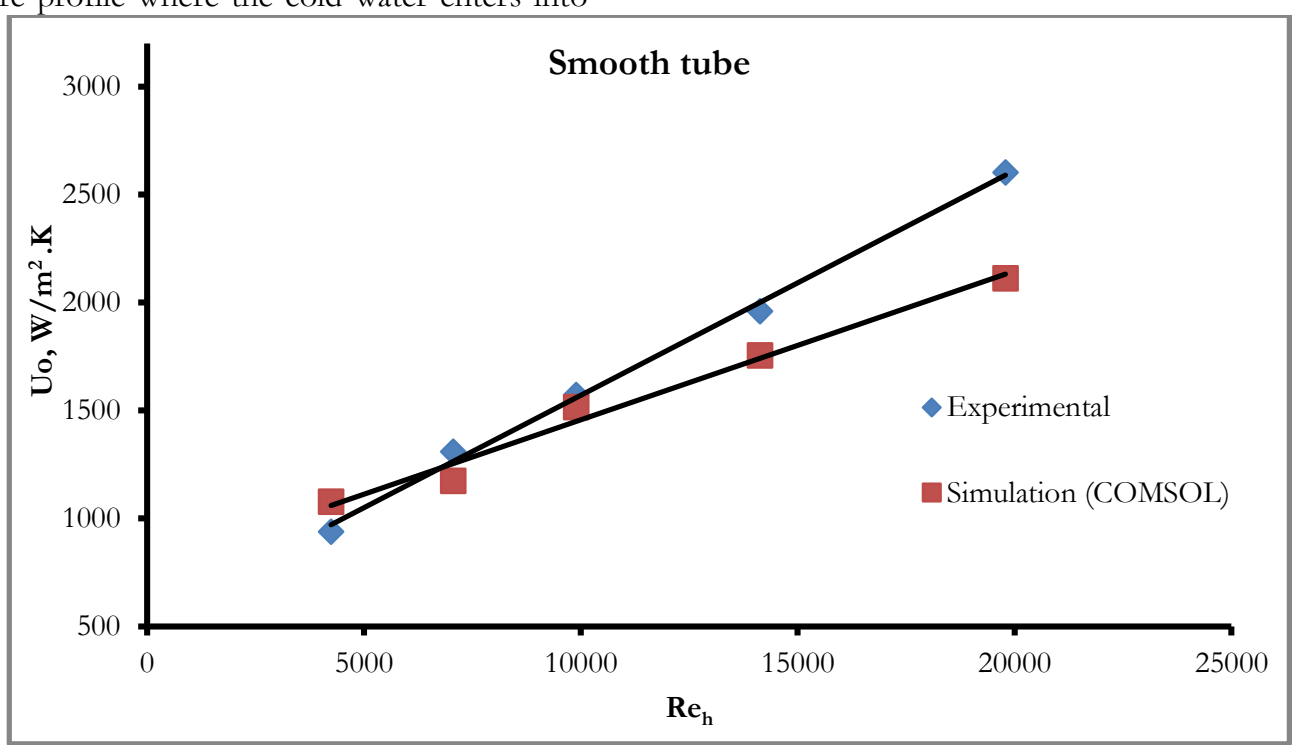

Figure (9): Comparison of experimental and simulation $\mathrm{U}_{\mathrm{o}}$ for smooth tube, $\mathrm{Rec}=18200$.

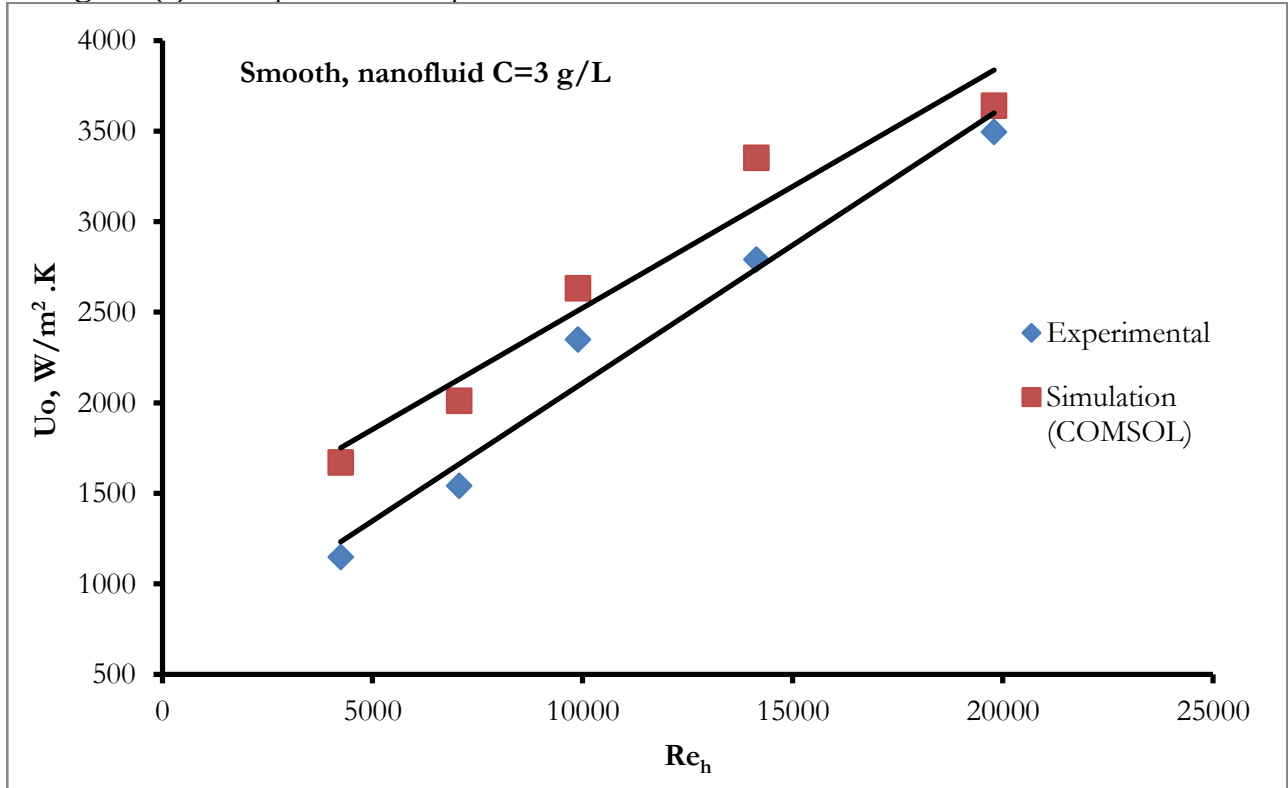

Figure (10): Comparison of experimental and simulation $U_{o}$ for smooth tube, $R e c=18200$. 


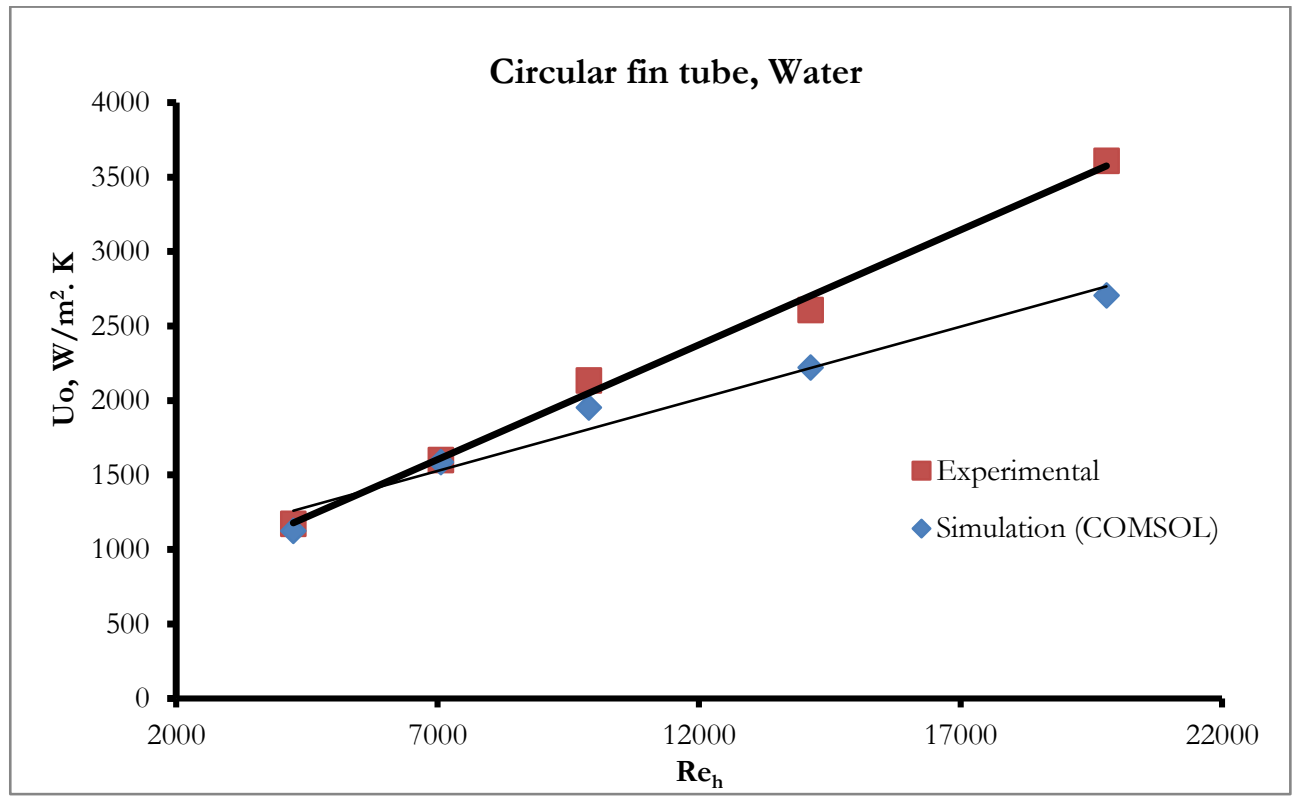

Figure (11): Comparison of experimental and simulation $U_{o}$ for circular fin tube, $\operatorname{Rec}=18200$.

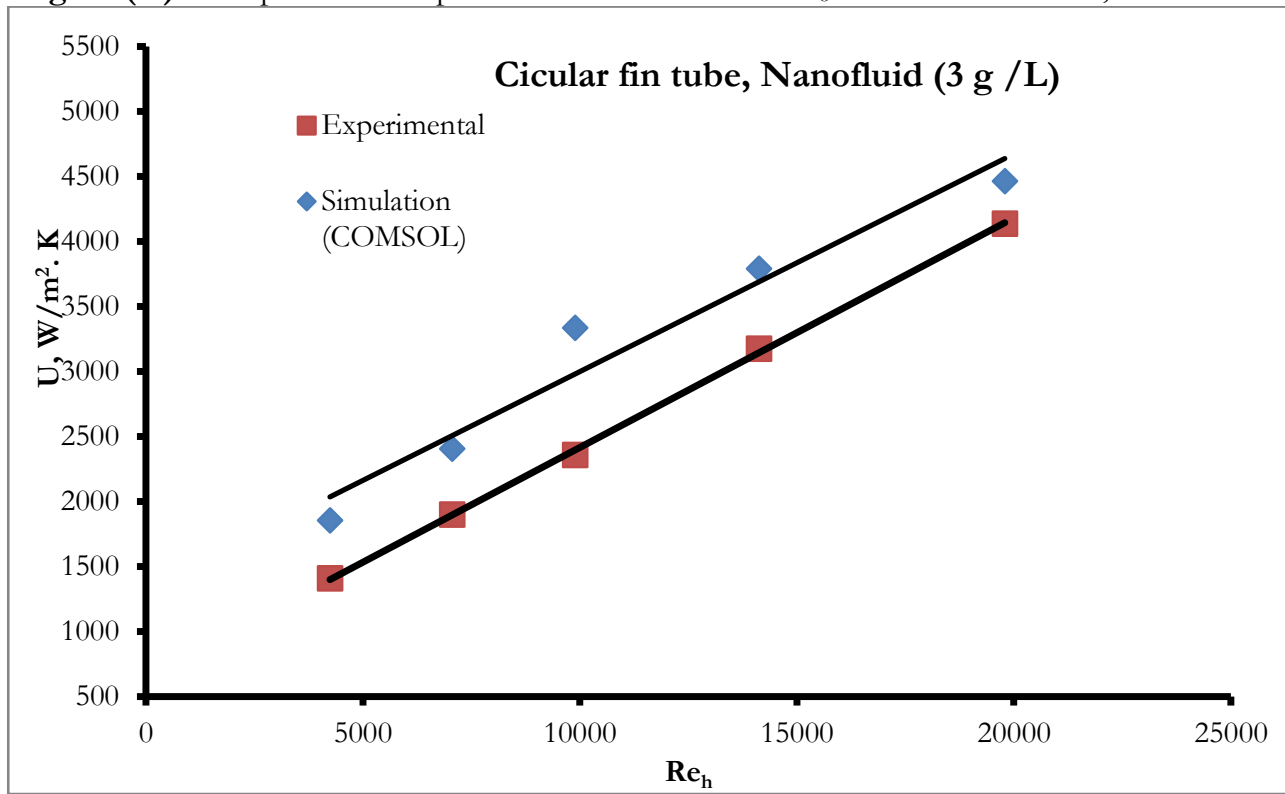

Figure (12): Comparison of experimental and simulation $U_{o}$ for circular fin tube with nanofluid, $\operatorname{Re}_{\mathrm{c}}=18200$.

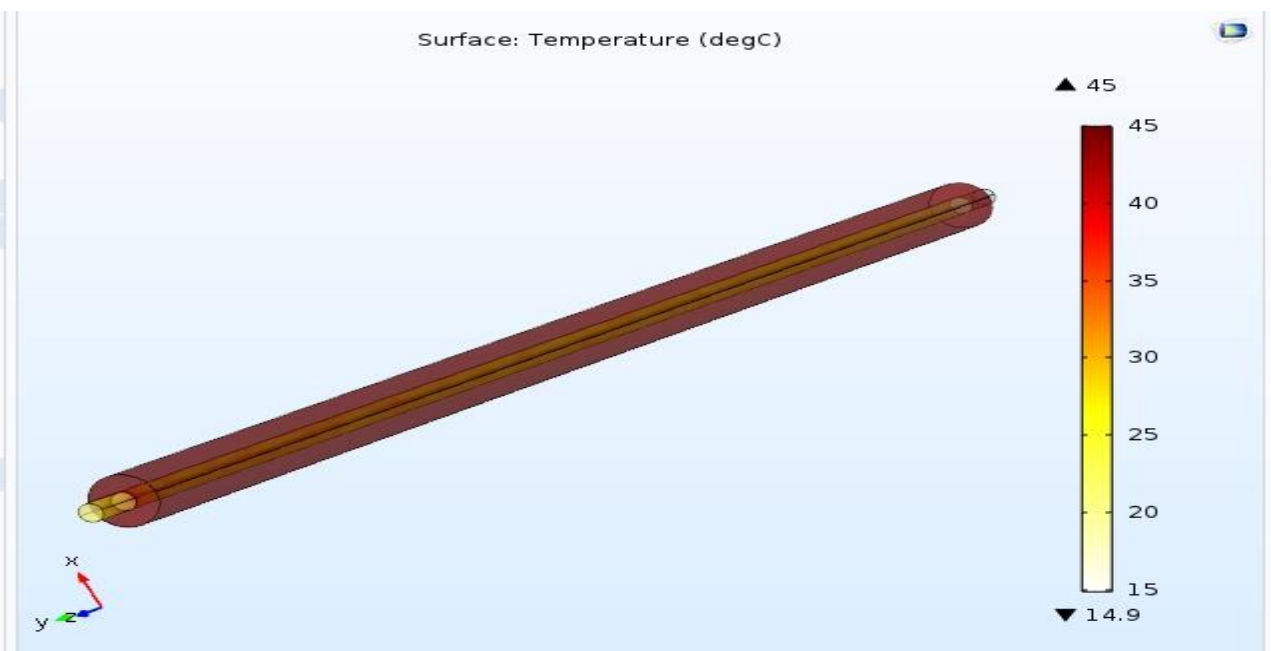

Figure (13a): Temperature profile around the smooth tube with water as a working fluid, $\operatorname{Re}_{\mathrm{h}}=19790, \operatorname{Re}_{\mathrm{c}}=5170$. 
Graphics Convergence Plot 1 Convergence Plot 2

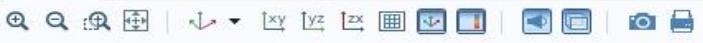

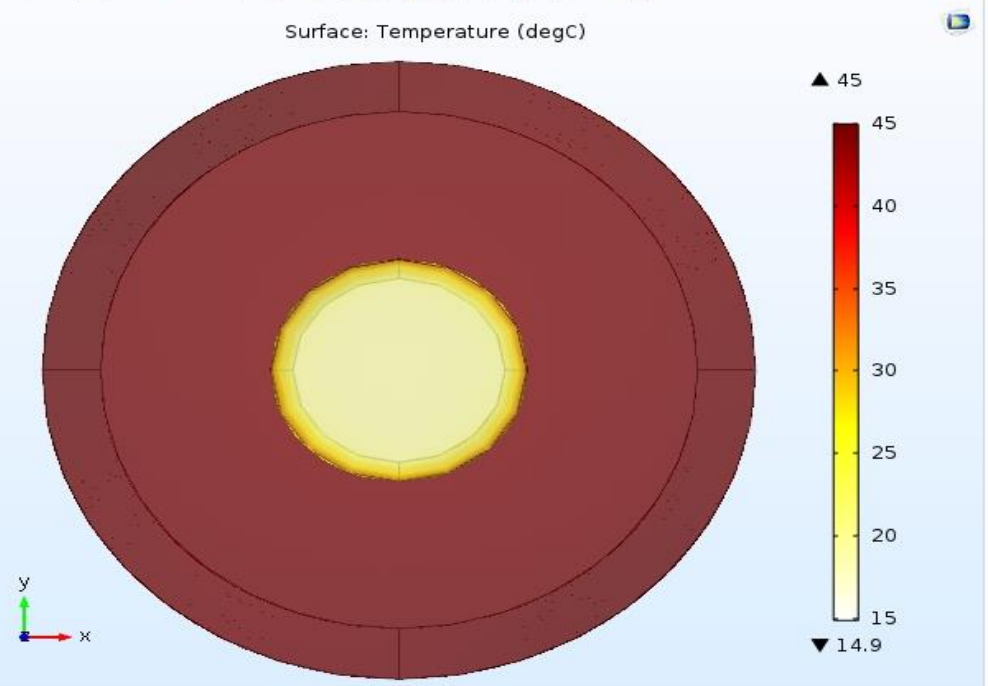

Figure (13b): Temperature profile front view of a smooth tube with water as a working fluid, $\operatorname{Re}_{\mathrm{h}}=19790$, $\operatorname{Rec}=5170$.

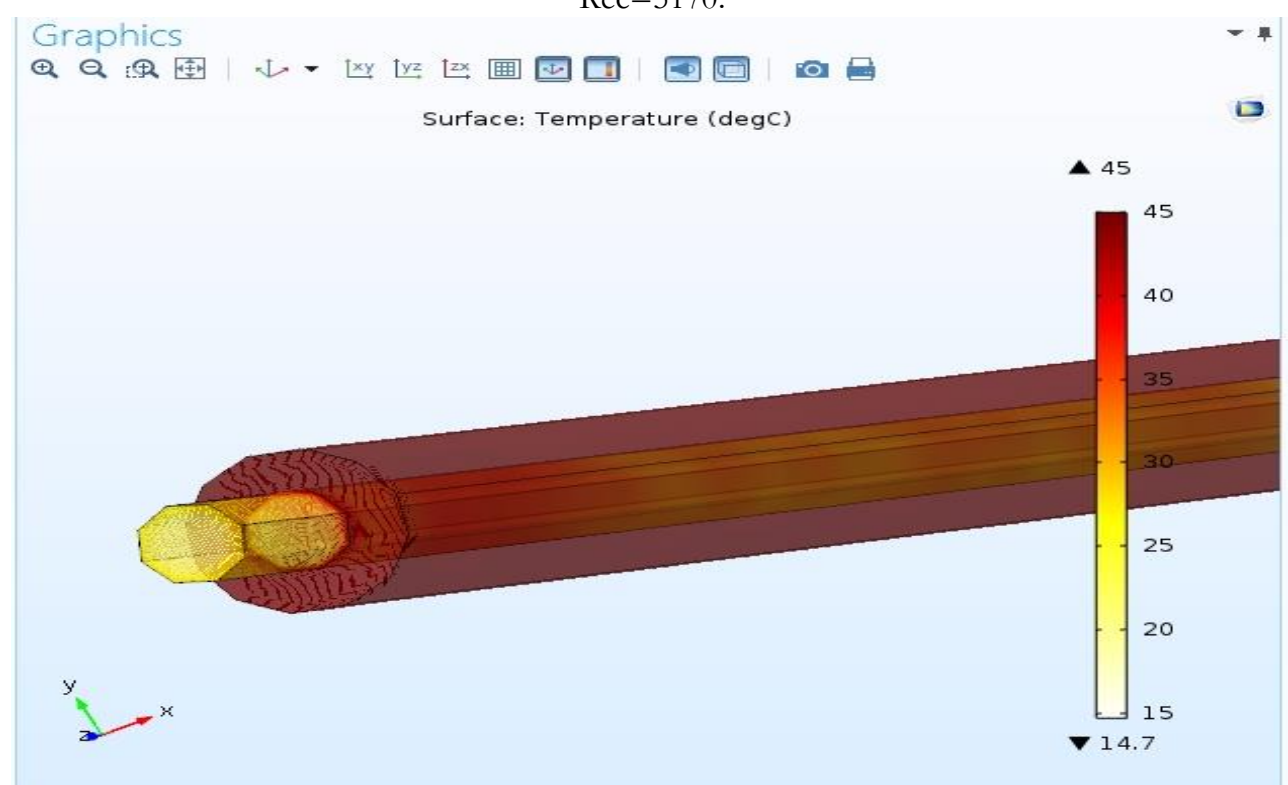

Figure(14a): Temperature profile around the finned tube with nanofluid, $\operatorname{Re}_{\mathrm{h}}=19790, \mathrm{Rec}=5170$.

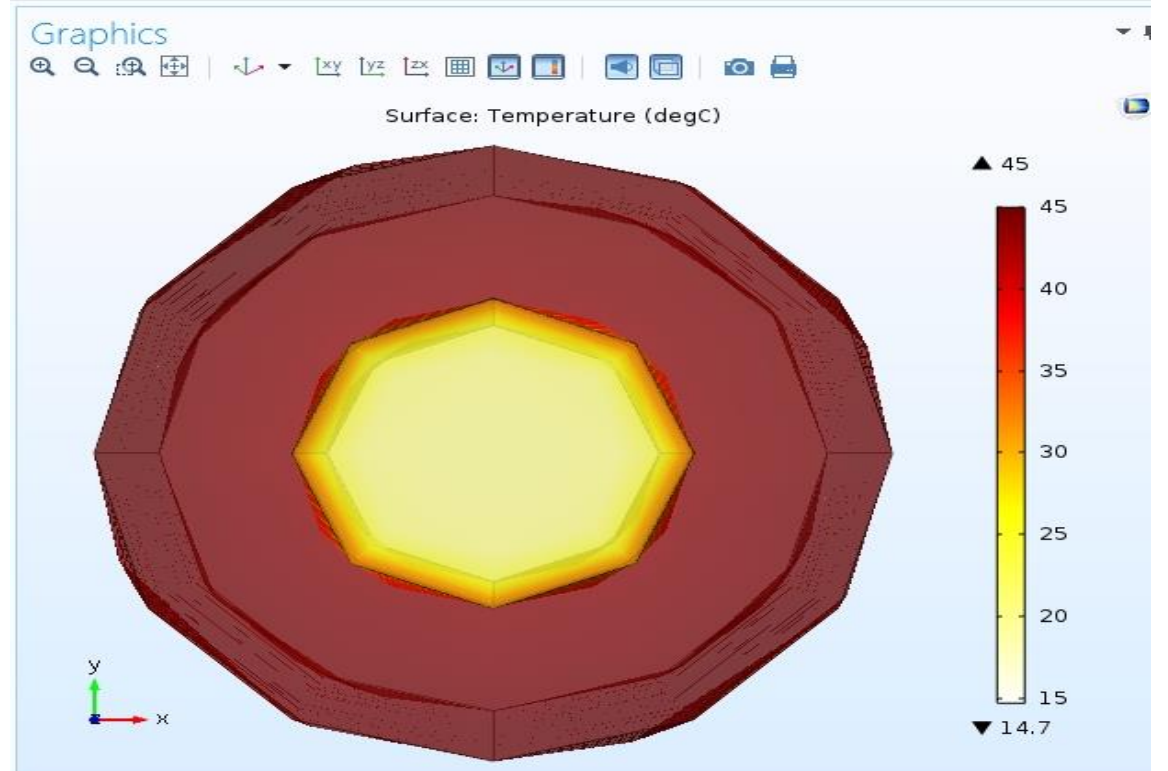

Figure (14b): Temperature profile for finned surface with nanofluid, $\operatorname{Re}_{\mathrm{h}}=19790, \mathrm{Rec}=5170$. 


\section{Conclusions}

Surface extension and aluminum oxide nanofluid both enhances the heat transfer rate when used individually in a manner dependent on the Reynolds number. The conjoint effect of both surface extension and nanofluid improves the heat transfer rate appreciably. The current work indicates that the increase in the nanofluid concentration up to $3 \%$ volume causes a linear increase in the overall heat transfer coefficient. In addition, 30\% average heat transfer enhancement is obtained by using circular fin at highest Reynolds number. Whereas, the use of nanofluid on smooth surface provides an average heat transfer enhancement by $33 \%$. The conjoint effect of $\mathrm{Al}_{2} \mathrm{O}_{3}$ of $3 \mathrm{~g} / \mathrm{L}$ concentration and circular fin provides average heat transfer enhancement by $53 \%$ for highest Re investigated. Increasing Re causes a clear increase of heat transfer enhancement on the finned surface while it shows unstable trend for nanofluid. The overall heat transfer coefficient predicted by CFD agrees reasonably well with the experiments. For the case of smooth tube without nanofluid, the thermal active region is concentrated close to the wall of inner tube. However, when using fins and nanofluid, the thermally active region is extended from the wall of inner tube to the inside surface of the shell.

\section{References}

[1] N. Y. Kim, Y. P. Lee, S. Y. Youn, J. S. Jurng, "A study on the pressure loss, heat transfer enhancement and fouling control in a vertical particulate flow"., KSME Journal, 1996,10 (4), 450.

[2] N. H. Kim, Y. P. Lee, " Hydrodynamic and heat transfer characteristics of glass bead-water flow in a vertical tube "., Desalination, 2001, 33, 233.

[3] H. K. Kang, B. C. Lee, S. W. Ahn, J. W. Choi, S. H. An, "Numerical and experimental analyses of anti-fouling and heat transfer in the heat exchanger with circulating fluidized bed, The Canadian Journal of Chemical Engineering"., The Canadian Journal of Chemical Engineering,2011, 240.

[4] W. Duangthongsuk, S. Wongwises,"Heat transfer enhancement and pressure drop characteristics of TiO2-water nanofluid in a doubletube counter flow heat exchanger ", International Journal of Heat and Mass Transfer,2009, 52, 2059.

[5] A. Zamzamian, S. N. Oskouie, A. Doosthoseini, A. A. Joneidi, M. Pazouki, " Experimental investigation of forced convective heat transfer coefficient in nanofluids of $\mathrm{Al}_{2} \mathrm{O}_{3} / \mathrm{EG}$ and $\mathrm{CuO} / \mathrm{EG}$ in a double pipe and plate heat exchangers under turbulent flow "., Experimental Thermal and Fluid Science,2011, 35 (3) 495.

[6] M. M. Sarafraz, V. Nikkhah, F. Hormozi, "Low-frequency vibration for fouling mitigation and intensification of thermal performance of a plate heat exchanger working with $\mathrm{CuO} /$ water nanofluid, Applied Thermal Engineering"., Applied Thermal Engineering.2017, 121, 388.

[7] H. S. Majdi, B. O. Hasan, Hussein A. Alabdly, M. M. Hathal, " Oil fouling in double pipe heat exchanger under liquid-liquid dispersion and the influence of $\mathrm{CuO}$ nanofluid, Unpublished Results, Department of Chemical Engineering, Al-Nahrain University, Iraq, 2019.

[8] J. Albadr, A. S. Tayal, M. Alasadi, Heat transfer through heat exchanger using $\mathrm{Al}_{2} \mathrm{O}_{3}$ nanofluid at different concentrations., Case Studies in Thermal Engineering, 2013,1, 38.

[9] M. S. Baba, A. V. Sita, R. Rajuc, M.B. Raod, Heat transfer enhancement and pressure drop of $\mathrm{Fe} 3 \mathrm{O} 4$-water nanofluid in a double tube heat exchanger with internal longitudinal fins, Case Studies in Thermal Engineering, 2018,12, 600.

[10] A. K. Tiwari, P. Ghosh, J. Sarkar," Heat transfer and pressure drop characteristics of $\mathrm{CeO}_{2} /$ water nanofluid in plate heat exchanger, Applied Thermal Engineering", Applied Thermal Engineering,2013, 57, 24.

[11] A. N. Khalifa, M. A. Banwan," Effect of Volume Fraction of $\gamma$-Al2O3 Nano-fluid on Heat Transfer Enhancement in a Concentric Tube Heat Exchanger, Heat Transfer Engineering, 2015, 36 (6), 1387-1396.

[12] A. M. Hussein, Bakar, R. A., Kadirgama, K., 2014., "Study of forced convection nanofluid heat transfer in the automotive cooling system", Case Studies in Thermal Engineering., Elsevier., 2., 50-61.

[13] A. A. Kramallah, N. S. Mahmoud, A. M. ALTajer, 2018, "Numerical Study of Heat Transfer and Flow of Nanofluid Using Multi-Phase Mixture Model through Elliptical Tubes"., Journal of University of Babylon for Engineering Sciences, Vol. (26), No. (6).

[14] B. Mehdi, R. Reza, Y. Ali, K. Erfan, M. Ramin, A. Mohammad, " Recent research contributions concerning use of nanofluids in heat exchangers: A critical review ".,Applied Thermal Engineering, 2018,133 (25), 137.

[15] B. O. Hasan, E. A. Jwair, R. A. Craig," The effect of heat transfer enhancement on the crystallization fouling in a double pipe heat exchanger", Experimental Thermal and Fluid Science, 2017, 86, 272.

[16] S. K. Kumar, K. Vasudev, M. Krishna," Numerical study of heat transfer in a finned double pipe heat exchanger"., World Journal of Modelling and Simulation,2015, 11(1), 43.

[17] I. M. Ali, M. A. Mussa, M. M. Mustafa," Experimental Investigation of Forced Convection Heat Transfer in Open Cell Copper Fins"., AlNahrain Journal for Engineering Sciences (NJES),2017, 20 (1), 272.

[18] B. K. Mahato, F. R. Stewrd, and L. W. Shimlit," Steel pipe corrosion under flow conditions-II"., Corros. Sci.,1968, 8, 773-783.

[19] J. P. Holman, Heat transfer, 10 ${ }^{\text {th }}$ Edition, McGraw Hill, Boston, 2010.

[20] Q. J. Slaiman, B. O. Hasan, "Study on corrosion rate of carbon steel pipe under turbulent flow conditions ", The Canadian Journal of Chemical Engineering,2010, 88 (6), 1114-1120.

[21] B. O. Hasan, G. J. Nathan, P. J. Ashman, R. A. Craig, R. M. Kelso, " The use of turbulence generators to mitigate crystallization fouling under 
cross flow conditions, Desalination", Desalination, 2012, 288 (1) 108.

[22] O. A. Mohsen, Experimental investigation and simulation of convective heat transfer through double pipe heat exchanger with different extended surfaces, MSC thesis, Chemical Engineering Department, Al-Nahrain University, Iraq 2018.

[23] Y. Xuan, Q. Li, Transfer enhancement of nanofluids", International Journal of Heat and Fluid Flow, 2000, 21, 58.

[24] M. M. Hathal, M.sc thesis, "Experimental study on the effect of turbulent dispersion on heat exchanger performance", Department of Chemical Engineering, Al-Nahrain University, Iraq, 2018.

[25] P. V. Shaw, T. J. Hanratty, Fluctuations in the local rate of turbulent mass transfer to a pipe wall", A. I. Ch. E. J., 1964, 13, 689.

[26] T. Mizushina, F. Ogino, Eddy Viscosity and universal velocity profile in turbulent flow in a straight pipe, J. Chem. Eng. of Japan,1970, 3, 166.

[27] D. B. De Graaff, D.R. Webster, J. K. Eaton, The effect of Reynolds number on boundary layer turbulence,"., Experimental Thermal and Fluid Science,1998, 18(4), 341.

[28] Q. J. Slaiman, M. M. Abu-Khader, B. O. Hasan," Prediction of heat transfer coefficient based on eddy diffusivity concept "., Trans. IChemE, Part A, Chem. Eng. Res. Design, 2007, 85 (A4), 455.

[29] B. O. Hasan, Heat transfer analysis in thermal entrance region under turbulent flow conditions, Asia pacific J. Chemical Eng., 2013, 8 (4) 578-592.

[30] C. S. Jwo, L. Y. Jeng, T. P. Teng, C. C. Chen, "Performance of Overall Heat Transfer in MultiChannel Heat Exchanger by Alumina Nanofluid ", Journal of Alloys and Compounds, 2010, 504, 385. 